\title{
Evaluating the Performance of Iraqi EFL College Students in Using Frequency Adverbs
}

\author{
Sabeeha Hamza Dehham ${ }^{1}$ \\ ${ }^{1}$ College of Education for Pure Sciences, University of Babylon, Babil, Iraq \\ Correspondence: Sabeeha Hamza Dehham, College of Education for Pure Sciences, University of Babylon, Babil, \\ Iraq. E-mail: sabeeha_dehham@yahoo.com
}

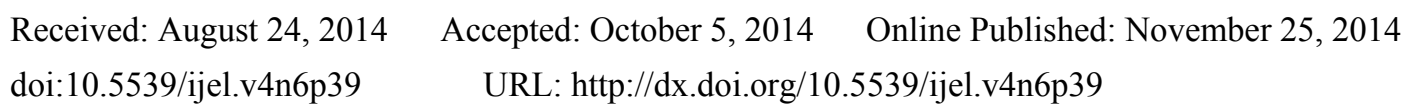

\begin{abstract}
Frequency adverb is used to express approximately how many times a customary or habitual action or condition is repeated. It is one of the essential constructions in English grammar and a problematic area for the Iraqi EFL university learners. The study aims at investigating the performance of Iraqi EFL university students in using frequency adverbs by form and function and finding out the area of difficulty in this regard and suggesting remedial work for the alleviation of these difficulties. It is hypothesized that Iraqi EFL learners encounter difficulties in using adverbs of frequency. The study begins with the theoretical aspect encompassing definitions, types, and functions of frequency adverbs in English. Then, the practical aspect represented in a diagnostic test applied to a random sample of (50) students taken from the fourth level in the Department of English ,College of Education for human Sciences, University of Babylon. The findings of the test show that Iraqi EFL university students face difficulty in using frequency adverbs which, in turn, verifies the hypothesis of the study. In the light of the results of the test, some conclusions are drawn and a number of suggestions and remedial work are presented so that the learners can overcome the difficulty they encounter in using adverbs of frequency in English.
\end{abstract}

Keywords: frequency adverb, performance, Iraqi EFL learners, error analysis

\section{Introduction}

\subsection{Introduce the Problem}

Adverbs refer to single words that modify verbs, adjectives, and adverbs. They answers the questions how, when, where, and why, and most of them modify or describe actions, states, or qualities. Any phrase or clause that is used as an adverb is called adverbial.

Parrot (2000) also defines adverbs as different kinds of words with quite different functions which occupy a range of positions in the sentence. He believes that choosing where to place them is often a major problem for the learner.

Hernández (2006:272) states that learning a foreign language generally implies making mistakes in various areas, especially in grammar. A very common type of mistake which learners make when producing grammatical structures involves the use of adverbs, specifically misplacing them in the sentence. This should not be surprising since adverbs are more difficult to define than nouns, verbs, and adjectives. Adverbs have many kinds of meanings and their grammar is quite complex. Regarding meaning, adverbs express ideas such as manner, time, and place (location or destination). Most adverbs of manner have a recognizable form; that is, they end in -ly. Some other adverbs cannot be easily recognized by their form because they do not have a specific suffix. Besides, they may modify almost any kind of construction in English: nouns, verbs, adjectives, other adverbs, and even whole sentences.

On the other hand, Stageberg (1971:216) mentions that there are numerous subclasses of one-word adverbials, and each subclass has its own positions in the various sentence patterns.

Moreover, many authors agree on the fact that adverbs are rather complex structures because of their various classifications, meanings and positions in the sentence. This complexity is due to the syntactical and semantic behavior of the adverb which is determined by its position in the sentence. Adverb position may not only change the meaning of the sentence but also make the sentence grammatical or ungrammatical (Bing, 1989; Celce-Murcia \& Larsen-Freeman, 1999; Parrot, 2000; Raimes, 2001). 
Thus, Iraqi EFL University learners face difficulty in using the order of frequency adverbs in English because adverbs are considered the most movable elements in English. Moreover, adverbs take different positions within the sentence. They can appear before the subject, between the subject and the verb, or at the end of the clause. In general, English adverbs do not come between the verb and the object.

\subsection{The Aims of the Study}

This study aims at:

1) Presenting a brief and relevant background of adverbs of frequency.

2) Identifying and classifying the errors made by fourth year students in English Department / College of Education for Human Sciences at Babylon University in the use of adverbs of frequency during the academic year $(2013-2014)$.

3) Locating the areas of difficulty Iraqi EFL learners encounter in learning adverbs of frequency.

\subsection{The Hypotheses}

It is hypothesis that:

1) There are difficulties and many errors in the order of frequency adverbs.

2) The students do not know the correct order and the position of such adverbs.

\subsection{Procedures}

1) Constructing a test to specify the errors made in the use of adverbs of frequency.

2) Classifying errors.

3) Analyzing results statically.

4) Drawing conclusions.

\subsection{Limits of the Study}

This study is confined to university learners at their fourth year in the Department of English, College of Education for Human sciences, University of Babylon during the academic year (2013-2014). The fourth year students have been chosen to apply the test, as they are supposedly the most advanced and qualified learners in the area of at the university level.

\subsection{Value of the Study}

This study is hoped to be valuable in providing pedagogical insights to those specialized in foreign language teaching and learning such as syllabus designers, learners, testers, textbook writers and teachers. It could also be useful for learners themselves since the study highlights the problematic spots they could find in the grammatical area concerned by relating the learner's erroneous responses to the possible reasons behind them.

\section{Adverbs}

Adverbs are words that modify verbs, adjectives, other adverbs and sentences (Yule, 2006:110). Greenbaum (1996:141) states that adverbs are heterogeneous class, varying greatly in their functions and positional ranges. They constitute a serious of overlapping subclasses, and some of them belong to more than one subclass. For example, the adverb very is an intensifier that functions only as premodifer (very large, very carefully) whereas too is an intensifier when it functions as premodifier (too small, too quickly), but it has a different meaning ('in addition') when it functions as an adverbial (the food was food, too).

Traditionally, adverbs can be classified into three types: (a) adverbs of time: now, soon, still, then, today...etc. (b) adverbs of place: by, down, here, near, up...etc. and (c) adverbs of manner: bravely, fast, happily, hard, well, quickly...etc. Each of these groups can be divided into subclasses. Adverbs of time, for example, can be subdivided into three kinds:

a. Adverbs of definite time, answering the question "when?": yesterday, last week, at three o'clock, early, tomorrow ,soon, late, now.

b. Adverbs of frequency, answering the question "How long?": always, never, seldom, rarely, frequently, often, sometimes, generally.

c. Adverbs of duration, answering the question "How long?": hours, for hours, a week, the whole night, until dawn, since yesterday. 


\subsection{Adverbs of Frequency}

Frequency adverbs say how often something happens. Praninskas (1975:52) states that Frequency adverbs are used to express approximately how many times a customary or habitual action or condition is repeated. They are not generally used with continuous tenses. They are generally used in positive sentences, but some adverbs can also be used in negative sentences. They are most often put in the middle, but in a special place in the middle: between the subject and the main verb, but after be alone. When there are several auxiliaries in a verb phrase, the adverb should be placed after the first one:

(1) Doug often watches movies on his computer.

(2) I rarely smoke cigarettes.

(3) He was always late for class. (Beare, 2004:3)

(4) We have never been invited to one of their parties.

(5) She must sometimes have wanted to run away.

For questions and negative statements, the adverb goes before the main verb, except the verb "to be":

(6) Why do they always complain?

(7) Who is she constantly talking to on the phone?

(8) They aren't usually nice.

(9) Doesn't ever he study? (Yule, 2006:116)

It is worth noted that negative adverbs like "never", "seldom", and "rarely" do not go at the end of the sentences. They can go at the beginning of the sentence to add a strong emphasis, but then the rest of the sentence must take a question form, even though it is a statement.

(10) Never have I seen such a beautiful woman!!

(11) Seldom does he work so late.

(12) Rarely do we have opportunity like this to.

Some adverbs of frequency come at the beginning of the sentence or at the end for emphasis:

(13) Usually we eat dinner at 6:00

(14) Occasionally I walk around the seawall.

(15) They go to church regularly.

(16) Traditionally, that was considered a child's play.

(17) Normally, I get up around 6 o'clock.

(18) Every night, we stay up late to study.

Finally Adverbs that tell the exact number of times (once, twice) usually come near the end of a sentence, but they can come at the beginning of a sentence, too:

(19) I have seen that movie twice.

Twice I went skiing when it was twenty below zero. Hernández (2006:272-3)

(20) Every once in a while I visit my grandmother in Minnesota.

I visit my grandmother in Minnesota every once in a while

\subsection{Classification of Frequency Adverbs}

Adverbs of frequency tell us how often something happens, and they can be either definite or indefinite. They are usually only used with the present simple tense because we are talking about repeated or habitual activities. Adverbs of frequency may be a one - word frequency (sometimes, often, usually......etc.), or a phrase frequency (three times, every month, now and then.... etc.)

(21) Students are always busy.

We have test every month

Adverbs of frequency can be classified into:

A. Adverbs of Definite Frequency 
Definite adverbs of frequency are more specific than indefinite adverbs of frequency. Some examples of definite adverbs of frequency:

Hourly, daily, weekly, monthly, yearly, annually.

Every minute, once an hour, quarterly.

Once, twice, three times, a million times.

Every day / hour / month / year / etc.

All the time, most of the time, most mornings / afternoon /evenings

Once in a while, once / twice / etc.

It is worth mentioned that definite adverbs of frequency can go at the beginning or end of a sentence. They never go in the middle of the sentence.

(22) The cleaning staff cleans the hotel rooms daily.

(23) Once in a while my mother babysits the kids

(24) Most businesses submit their taxes quarterly.

(25) The bell rings every hour.

(26) I've seen that film twice. (Yule, 2006:116)

B. Adverbs of indefinite Frequency

These adverbs say how often something happens. The following table shows relative frequencies of adverbs:

Table 1. Relative frequencies of the adverbs

\begin{tabular}{ll}
\hline ADVERB & FREQUENCY \\
\hline Never & 202 \\
Often & 153 \\
Always & 141 \\
Ever & 103 \\
Sometimes & 63 \\
Usually & 51 \\
Generally & 39 \\
Normally & 20 \\
Constantly & 16 \\
Rarely & 16 \\
Regularly & 16 \\
Frequently & 15 \\
Repeatedly & 15 \\
Routinely & 11 \\
Occasionally & 7 \\
Almost never & 3 \\
Seldom & 3 \\
\hline
\end{tabular}

Adverbs of indefinite frequency usually go in the middle of the sentence before the main verb, except the verb "to be". (see 2.1)

The most common adverbs of frequency can be classified as follows:

1. Always: at all times; without exception:

(27) The sun always rises in the east. (Hornby, 1980:26)

(Always may be modified by almost, nearly or not)

(28) He's nearly always at home.

I 'm not always at home on Sundays. (Hornby, 1980:26)

2. Constantly: continuously; frequently (Ibid.182)

(29) Shopping centers are constantly packed with people.

Who is she constantly talking to on the phone? 
3. Usually: in the way that is usual:

(30) What do you usually do on Sundays?

He's usually early.

4. Generally: usually; as a general rule:

(31) I generally get up at six o'clock. (Ibid.357)

5. Normally: usually; regularly; commonly nowadays:

(32) He normally gets good marks in exams. (Chile, 2003:2)

I'm not normally this irritable.

They normally travel by car.

6. Regularly: in a regular manner; at regular intervals (times)

(33) A garden regularly laid out.

Katy regularly practices the piano.

7. Often: many times; in a large proportion of instances:

(34) We often go there.

We have often been there. (Hornby, 1980:584)

8. Frequently: often

(35) Is she frequently at home then? (Praninskas,1975:53)

He frequently reads in bed. (Stageberg,1971:220)

9. Sometimes: at some times; now and then; from time $\mathrm{t}$ time:

(36) I sometimes have letters from him.

Sometimes we go to the cinema and at other times we go for a walk.

When sometimes is used in a contrasting statement, or when it repeated, it may follow the verb:

(37) She likes sometimes the one and sometimes the other.

(38) He says sometimes the one thing and at other times the exact opposite. (Hornby, 1980:822)

10. Occasionally: now and then; at times:

(39) He visits me occasionally. (Ibid.580)

I go there occasionally. (Swan, 1980,22)

They could occasionally be heard laughing. (Chile, 2003:3)

11. Once in a while: now and then; occasionally; a few times:

(40) I go to the cinema once in a while.

Every once in a while I visit my grandfather in Minnesota.

12. Rarely: seldom:

(41) I rarely eat in restaurants.

He visits us only rarely nowadays. (Ibid.695)

13. Seldom: not often; rarely:

(42) I have seldom seen such large apples.

Seldom do I go to bed before midnight.

We had seldom walked to the park. (Stageberg, 1971:220)

Seldom have I seen such a remarkable creature. (Swan, 1980:299)

14. Hardly ever: It has negation in meaning: almost no; almost not; very seldom:

(43) Hardly had I arrived when trouble started. (Ibid.)

He hardly ever goes to bed before night. (Hornby, 1980:m391) 
I would hardly ever be unkind to someone. (Chile, 2003:4)

15. Scarcely (ever): barely; not quite; almost not:

(44) There were scarcely a hundred people present.

Scarcely had he entered the room when the phone rang? (Hornby, 1980:759)

I had scarcely closed my eyes when the phone rang. (Swan, 1980:299)

16. Never (almost never): at no time; on no occasion:

(45) She never goes $t$ the cinema.

He has never been abroad.

17. Traditionally: (commonly in the past):

(46) Traditionally, that was considered child's play.

18. Twice: two times; as much; as many :

(47) I've been there once or twice.

He's twice the man he was. (Hornby, 1980:932)

19. Every now and again (then): occasionally ;from time to time:

(48) He drinks wine every now and again.

Do you relax now and then.

We go to the opera now and then. (Ibid.575)

20. From time to time: occasionally; now and then:

(49) My computer freezes from time to time.

from time to time I visit my grandfather. (Ibid.905)

21. Infrequently: not frequently: rarely:

(50) Selma infrequently catches the 9:15 bus to town.

22. Every week / year: always; whenever; common or familiar:

(51) We have a test every month.

She cleans her bedroom every week.

23. Nowadays: at the present time:

(52) Nowadays children prefer TV to reading. (Iibid.575)

Nowadays most people have a mobile phone.

24. Continually: again and again; without stopping:

(53) He drinks milk continually.

25. Repeatedly: again and again:

(54) She cleans her teeth repeatedly.

26. Ever: at any time: A-usually in negative and interrogative sentences expressing doubt or conditions:

(55) Nothing ever happens in this village.

Do you ever wish you were rich?

B-at any time up to the present (with present perfect tense, in questions):

(56) Have you ever been up in a balloon?

C- We use ever in questions and negative statements:

(57) Have you ever been to New Zealand?

I haven't ever been to Switzerland. (Chile, 2003:3)

\section{The Test}

A language test is a systematic method and a means of checking the student's performance through the elicitation of certain behaviour to make inferences about certain characteristics of an individual (Bachman, 1990:20). The test 
is designed to locate the precise area of difficulty faced by Iraqi EFL university students in using frequency adverbs and identifying the causes and the types of their errors.

The sample of the test is (50) learners taken randomly from the fourth stage / Department of English/College of Education for Human Sciences /University of Babylon during the academic year 2013 - 2014.

The test consists of one question of twenty five items and each item has randomly words and the students' task is to rearrange them correctly order using frequency adverbs in right positions.

\subsection{Item Analysis}

Davis (1968:162) states that "items analysis is a means of speculating how much information each single item contributes to the information by the test as a whole". The most widely used types of item analysis are the discrimination index and the facility value (Baker, 1989: 51).

\subsubsection{Item Discrimination Index (DI) and Facility Value (FV) of the Test's Items}

Item discrimination index refers to the degree to which it discriminates between students, with high and low achievements. Such item discrimination has the following formula:

$\mathrm{DI}=$ Correct $\mathrm{U}-$ Correct $\mathrm{L} / \mathrm{N}$

The following formula can be illustrated as follows:

$\mathrm{DI}=$ represents "discrimination index"

$\mathrm{U}=$ represents "upper half"

$\mathrm{L}=$ represents "lower half"

$\mathrm{N}=$ represents "the number of the students taking the test in one group"

Facility value, on the other hand, refers to the percentage of students who answer the item correctly and it shows how easy or difficult the item is. The facility value of an item can be calculated by dividing the number of correct answers by the number of students. the following formula is used to find out the level of difficulty for each item in the test:

$\mathrm{FV}=\mathrm{R} / \mathrm{N}$

The following formula can be illustrated as follows:

FV: represents "item facility value"

$\mathrm{R}=$ represents "the number of correct answers"

$\mathrm{N}=$ represents "the number of the students taking the test"

The following tables show the discrimination index and the facility value of the items of the test:

Table 2. The discrimination index and the facility value of the tests items

\begin{tabular}{lll}
\hline No. of Items & DI & FV \\
\hline 1 & 0.63 & 0.60 \\
2 & 0.46 & 0.52 \\
3 & 0.45 & 0.34 \\
4 & 0.46 & 0.42 \\
5 & 0.82 & 0.78 \\
6 & 0.34 & 0.46 \\
7 & 0.25 & 0.32 \\
8 & 0.48 & 0.42 \\
9 & 0.56 & 0.40 \\
10 & 0.69 & 0.60 \\
11 & 0.82 & 0.62 \\
12 & 0.31 & 0.24 \\
13 & 0.26 & 0.14 \\
14 & 0.79 & 0.50 \\
15 & 0.57 & 0.46 \\
16 & 0.78 & 0.42 \\
17 & 0.50 & 0.48 \\
18 & 0.75 & 0.52 \\
\hline
\end{tabular}




\begin{tabular}{lll}
\hline 19 & 0.19 & 0.32 \\
20 & 0.47 & 0.42 \\
21 & 0.67 & 0.54 \\
22 & 0.56 & 0.42 \\
23 & 0.45 & 0.48 \\
24 & 0.32 & 0.24 \\
25 & 0.16 & 0.26 \\
\hline The Mean & 0.56 & 0.48 \\
\hline
\end{tabular}

This table shows the following results:

1) There is no negative discrimination index for any item since all test items have positively valued discrimination indices. The (DI) of the item ranges from (0.16) to $(0.82)$ which refers to the individual differences among the learners. The mean of the (DI) for the whole test is acceptable as the acceptable range of (DI) of the test items stands between (0.20 and 0.90) according to (Mousavi,1997: 69).

2) The facility values of the test items range between (0.14) and (0.78) which are very apart and the mean of (FV) of the whole test is $(0.48)$ which is acceptable.

\section{Results of the Subject's Responses}

The following table summarizes the performance of the students in the test's items:

Table 3. The performance of the students in the test's items

\begin{tabular}{|c|c|c|c|c|c|c|c|c|c|}
\hline No. of & No. of Correct & & No. of Incorrect & & No. of & No. of Correct & & No. of Incorrect & \\
\hline Item & Responses & $\%$ & Responses & $\%$ & Item & Responses & $\%$ & Responses & $\%$ \\
\hline 1 & 30 & 60 & 20 & 40 & 14 & 25 & 50 & 25 & 50 \\
\hline 2 & 24 & 52 & 26 & 48 & 15 & 23 & 46 & 27 & 54 \\
\hline 3 & 17 & 34 & 33 & 66 & 16 & 21 & 42 & 29 & 58 \\
\hline 4 & 21 & 42 & 29 & 58 & 17 & 24 & 48 & 26 & 52 \\
\hline 5 & 39 & 78 & 11 & 22 & 18 & 26 & 52 & 24 & 48 \\
\hline 6 & 23 & 46 & 27 & 54 & 19 & 16 & 32 & 34 & 68 \\
\hline 7 & 16 & 32 & 34 & 68 & 20 & 21 & 42 & 29 & 58 \\
\hline 8 & 21 & 42 & 29 & 58 & 21 & 27 & 54 & 23 & 46 \\
\hline 9 & 20 & 40 & 30 & 60 & 22 & 21 & 42 & 29 & 58 \\
\hline 10 & 30 & 60 & 20 & 40 & 23 & 24 & 48 & 26 & 52 \\
\hline 11 & 31 & 62 & 19 & 38 & 24 & 12 & 24 & 38 & 76 \\
\hline 12 & 12 & 24 & 38 & 76 & 25 & 13 & 26 & 37 & 74 \\
\hline 13 & 07 & 14 & 43 & 86 & Total & 544 & 43.52 & 706 & 56.48 \\
\hline
\end{tabular}

According to the results of the test, the number and percentage of the incorrect responses in the whole test are (706, $56.48 \%$ ) which are more than that of correct responses (544, 43.52\%). These results indicate that the students encounter difficulty in using adverbs of frequency in English and this in turn verifies the hypothesis of the study.

\section{Errors Analysis}

Errors analysis is a type of linguistic analysis that focuses on the errors that the learners make. It involves a comparison between the errors made in the target language and the target language itself.

\section{Sources of Errors}

Brown (1987:177) mentions four factors to which students' errors can be attributed. They are interlingual transfer, interalingual transfer, context of learning, and communication strategies.

\subsection{Interlingual Transfer}

Ellis (1984:48) states that many errors result from the influence of the mother tongue. In an attempt to make up the deficiencies of his knowledge of the target language, the learner may recourse to the appropriate parts of the native language. Some of the students' responses to Item (3), (6), (8) and (18) can reflect this influence:

Item (3) * Who constantly is she talking to on the phone?

Item (6) * The rain generally is finished by three in the afternoon.

Item (8) * Have I never seen such a crowd! 
Item (18) * Shopping centers frequently are packed with people.

Interlingual transfer has been found to explain $(9.78 \%)$ of all students' error.

\subsection{Intralingual Transfer}

Richards (1974:6) states that intralingual errors are items produced by the student which do not reflect the structure of the mother tongue. These are due to the generalizations based on partial exposure to the target language. Such errors may be attributed to certain factors:

a. Overgeneralization: which refers to the incorrect application of the previously learned material to a present foreign language context.

b. Ignorance of rule restrictions: which leads the students to apply some rule to a category to which it is not applicable.

c. Incomplete application of rules: which involves a failure to learn more complex types of structure rules.

d. False concepts hypothesized: that may derive from faulty comprehension of a distinction in the target language.

The items (4), (6), (15), (16) and (24) can illustrate the subjects' strategy of overgeneralization:

Item (4) * How do often you go to the restaurant?

Item $(6) *$ The rain generally is finished by three in the afternoon.

Item (15) * John usually does not work late.

Item (16) * I rarely am in the city on Sundays.

Item (24) * They could be occasionally heard the laughing.

The items (1), (7), (11), and (21) are examples of the students' ignorance of rules restrictions:

Item $(1) *$ She sometimes is late.

Item (7) * Twice a month we go to the theatre.

Item (11) * Rooms daily are cleaned.

Item $(21) *$ Do you always carry a briefcase?

The items (10), (13) and (17) are examples of the strategy of incomplete applications of rules:

Item (10)* They get usually home at six o'clock.

Item (13) * Hardly ever they stay at home a night on Saturday

Item (17) * I seldom have seen such large apples.

The items (6), (9), (19)* and (23) can illustrate the false concepts hypothesized:

Item $(6) *$ The rain is finished by three in the afternoon generally.

Item (9) * I scarcely know him.

Item (19) * Have ever you been to Japan?

Item (23) * My mother every once a while babysits the kids.

The percentage of such errors is $(43.34 \%)$ of the total errors.

\section{3 Context of Learning}

Errors of context of learning refer to the negative influence of elements of learning situation, such as the classroom, the lecture, and the curriculum. These kinds of errors are also called "induced errors", which refer to the errors caused by the way in which language items have been taught (Van Patten, 1990: 4). The impact of the context of learning can be found in items (15), (17), (20) and (22) of the test:

Item (15)* John usually does not work late.

Item (17) * Seldom I have seen such large apples.

Item (20)* She does sometimes her shopping on Fridays.

Item (22) * Normally I get up around 6 o'clock.

The percentage of such errors is $(33.15 \%)$ of the total errors. 


\section{4 Communication Strategies}

Communication strategies are used by learners to overcome a communication problem caused by a lack of or inability to access L2 knowledge (Ellis, 2003:340).Second language learners will inevitably experience moments where there is a gap between communication intent and their ability to express that intent. Some learners may just stop talking; others will try to express themselves using communication strategies (Yule, 2006:197). Corder (1981:104) states that the subjects' errors in communication strategies are due to reduction or avoidance strategies .He calls the first one as "risk-avoidance" and the second one as "risk -taking" or "resources expansion".

"Avoidance" is one of these strategies. It means not saying what one wants to say, so one has the ability to solve the problem of how to express it (Yule, 2006:197).According to this strategy, the subjects may tend to give no responses or make no choices. In other words, avoidance strategy has been used and represented by the items that were left by the subjects with no responses.

The influence of this strategy can be seen in items $(6,8,11,14,21,23$ and 24) which the subjects left these items without answer.

Paraphrasing( circumlocution), on the other hand, is another strategy. It is classified under what is called risk-taking strategies. To use paraphrase or circumlocution is to get round the problem with the knowledge available, which is perhaps intelligent, but successful (Corder,1981: 105). Some of these errors of this strategy can be clarified in items $(4,6,9,16$, and 22$)$ :

Item (4) * How do you often go to the restaurant?

Item $(6) *$ The rain generally is finished by three in the afternoon.

Item (9) * I know scarcely him.

Item (16) * Rarely I am in the city on Sundays.

Item (22)* Normally I get up around 6 o'clock.

The percentage of such errors is $(13.73 \%)$ of the total errors.

\section{Conclusions}

According to the findings of the test which has been applied to a random sample of Iraqi EFL university learners (50 students) from the department of English/ College of Education for human sciences/ University of Babylon. The total number and percentage of the incorrect responses are $(706,56.48 \%)$ which are more than that of correct responses $(544,43.52 \%)$. These results indicate that the students face difficulty in using frequency adverbs in English and these results confirm the hypothesis of the study.

The poor performance of the learners can be attributed to the following strategies:

a. Intraligual transfer has the majority of students' errors because it accounts for (43.34\%) of the total errors. These errors are related to different grammatical errors committed by the students.

b. The effect of context of learning constitutes (33.15\%) which is the second rate of errors.

c. The students' use of communicative strategies in the third rate of errors $(13.73 \%)$ when the students attempt to structure what they mean.

d. Interlingual interference constitutes $(9.78 \%)$ which is the fourth rate. These errors are related to the use of the rules of the native language and the use of literal translation by the students.

\section{Recommendations}

In the light of the discussion of the results of the present study, the following recommendations can be posited:

1) More emphasis should be given to the topic under investigation at all levels of education.

2) English adverbs must be taught by means of communication tasks and real -life situations which provide meaning or in the form of conversation.

3) More practices and exercises should be conducted among students in English frequency adverbs so that the students can recognize the types of these adverbs .

4) Depending on the types of the errors made by the subjects of this study, the teachers/ instructors should take these errors into consideration and ask their students to avoid such errors.

5) Due attention should be giving to teaching adverbs in English as it is a problematic area for Iraqi EFL university learners. 


\section{References}

Bachman, L. F. (1990). Fundamental Considerations in Language Testing. Oxford: Oxford University Press.

Baker, D. (1989). The Language Testing. London: Edward Arnold.

Beare, K. Adverbs of Frequency: English as 2nd Language.

Bing, J. (1989). English Grammar in Context. New Jersey: Prentice-Hall Regents.

Brown, D. (1987). Principles of Language Learning and Teaching (2nd ed.). Englewood Cliffs: Prentice-Hall, Inc.

Carter, R., Hughes, R., \& McCarthy, M. (2000). Exploring Grammar in Context. Cambridge: Cambridge University Press.

Celce-Murcia, M., \& Larsen-Freeman, D. (1999). The Grammar Book: An ESL/EFL Teacher's Course. Boston: Heinle \& Heinle Publishers.

Chile, W. (2003). Adverbs of Frequency.

Corder, S. P. T. (1981). Error Analysis and Interlanguage. Oxford: Oxford University Press.

Davis, A. (Ed.). (1968). Language Testing Symposium: A Psycholinguistic Approach. London: Oxford University Press.

Ellis , R. (2003). A Task - based Language Learning and Teaching. Oxford: Oxford University Press.

Ellis, R. (1984). Understanding Second Language acquisition. Oxford: Pergamum Institute of English.

Greenbaum, S., \& Quirk, R. (1996). Student's Grammar of the English Language. London: Longman.

Hernández, M. S. (2006). The Position of Adverbs in English: Trying to solve a major problem most Language Learners usually face. Filología Lingüistica, XXXII(1), 271-285.

Hornby, A. S. (1980). Oxford Advanced Learner's Dictionary of Current English. Oxford: Oxford University Press.

Mousavi, S. A. (1979). A Dictionary of Language Testing. Shiraz: Rahnama Publications.

Parrot, M. (2000). Grammar for English Language Teachers. Cambridge: Cambridge University Press.

Praninskas, J. (1975). Rapid Review of English Grammar. London: Prentice Hall INC.

Raimes, A. (2001). Grammar Troublespots: An Editing Guide for Students. Cambridge: Cambridge University Press.

Richards, J. C. (1980). A Non-Contrastive Approach to Error Analysis: Perspective on Second Language Acquisition. London: Longman.

Richards, J. C. (Ed.). (1974). Error Analysis. Singapore: Longman.

Stagebeg, N. C. (1971). An Introductory English Grammar. New York: Holt, Rinchart and Winston.

Swan, M. (1980). Practical English Usage. Oxford: Oxford University Press.

VanPatten, B. (1990). Second Language Acquisition Research and Foreign Language Teaching. Cambridge: Newbury.

Yule, G. (2006). The Study of Language (2nd ed.). Cambridge: Cambridge University Press.

\section{Appendix A}

\section{The Test}

Q.1 Put the words in the correct order to make sentences with adverbs of frequency:

1. late / is / she / sometimes

2. early / up / sister / never / Sundays / on / gets / my

3. is /she/ to /talking/ who/on/ phone/the/constantly/ ?

4. go / you / restaurant / often / a / do / how / to /?

5. she / the / beach / to / always / goes / in / the /summer

6. sometimes / her / does / she / Fridays / on / shopping 
7. go / we / twice / month / the / theatre / to / a

8. a /seen / I / crowd / ! / never/ have/ such

9. him / know/ scarcely / I

10. home / they / get / six o'clock / usually / at

11. are / /daily/ rooms/ cleaned

12. /every / she / now / drinks/coffee / then / and/

13. home/ night / they /Saturday / stay /at/ a/ hardly ever / on

14. the /once / cinema /we/ week/ go/ a/ to

15. does/ Peter/not/ usually/ late/so/work

16. in/city/rarely/on/am/the/Sundays/I

17. seen /have/ seldom/ large /such/ / apples/ I

18. shopping / people / frequently/ centers /are / with/ packed

19. ever / to/ have/ Japan /been/ you / ?

20. rain/generally/is/by/ finished/three/ the/ afternoon/in

21. ? / always /you / do / briefcase / a / do / carry

22. I / up/ 6 o'clock/normally/ around/ get

23. mother / a / in/ while/ Once / the kids/ babysits/my/every

24. could/occasionally/they/heard/be/ laughing

25. practices/ Katy / the/ regularly/ piano

\section{Appendix B}

\section{The Possible Answers of the Test}

1 . She is sometimes late.

2. My sister never gets up early n Sundays.

3. Who is she constantly talking to on the phone?

4. How often do you go to the restaurant?

5. She always goes to the beach in the summer.

6. The rain is generally finished by three in the afternoon.

7. We go to the theatre twice a month.

8. Never have I seen such a crowd!

9. I know him scarcely.

10. They usually get home at six o'clock.

11. Rooms are cleaned daily.

12. She drinks coffee every now and then.

13. They hardly ever stay at home a night on Saturday.

14. We go to the cinema once a week.

15. John does not usually work late.

16. I am rarely in the city on Sundays.

17. I have seldom seen such large apples.

18. Shopping centers are frequently packed with people.

19. Have you ever been to Japan?

20. She sometimes does her shopping on Fridays. 
21 . Do you always carry a briefcase?

22. I normally get up around 6 o'clock.

23. My mother babysits the kids every once a while.

24. They could occasionally be heard the laughing.

25 . Katy regularly practices the piano.

\section{Copyrights}

Copyright for this article is retained by the author(s), with first publication rights granted to the journal.

This is an open-access article distributed under the terms and conditions of the Creative Commons Attribution license (http://creativecommons.org/licenses/by/3.0/). 